\title{
G-protein coupled receptors of the renin-angiotensin system: new targets against breast cancer?
}

\section{Sylvie Rodrigues-Ferreira and Clara Nahmias*}

Inserm U981, Institut Gustave Roussy, Villejuif, France

\section{Edited by:}

Claudio M. Costa-Neto, University of Sao Paulo, Brazil

\section{Reviewed by:}

Kevin D. G. Pfleger, Harry Perkins Institute of Medical Research,

Australia

Roger Chammas, Universidade de

São Paulo, Brazil

*Correspondence:

Clara Nahmias, Inserm U981, Institut Gustave Roussy, 114 rue Edouard Vaillant, Molecular Medicine B2M, 94800 Villejuif, France

e-mail:clara.nahmias@inserm.fr
G-protein coupled receptors (GPCRs) constitute the largest family of membrane receptors, with high potential for drug discovery. These receptors can be activated by a panel of different ligands including ions, hormones, small molecules, and vasoactive peptides. Among those, angiotensins [angiotensin II (Angll) and angiotensin 1-7] are the major biologically active products of the classical and alternative renin-angiotensin system (RAS). These peptides bind and activate three different subtypes of GPCRs, namely AT1, AT2, and Mas receptors, to regulate cardiovascular functions. Over the past decade, the contribution of several RAS components in tumorigenesis has emerged as a novel important concept, Angll being considered as harmful and Ang1-7 as protective against cancer. Development of selective ligands targeting each RAS receptor may provide novel and efficient targeted therapeutic strategies against cancer. In this review, we focus on breast cancer to summarize current knowledge on angiotensin receptors (AT1, AT2, and Mas), and discuss the potential use of angiotensin receptor agonists and antagonists in clinics.

Keywords: GPCR, Angiotensin, ARBs, Mas, breast cancer, therapy
The RAS is an endocrine system that plays a central role in cardiovascular and renal physiology through regulation of blood pressure and sodium balance. Deregulated RAS may contribute to pathogenesis such as atherosclerosis, ischemic disease, hypertension, and heart failure. The physiological effects of the RAS are mediated by bioactive angiotensin peptides generated by enzymatic cascades and released in the systemic circulation as well as locally in various tissues (Crowley and Coffman, 2012). The "classical RAS" produces the AngII octapeptide through cleavage of inactive AngI by angiotensin converting enzyme (ACE), whereas the "alternative RAS axis" (Santos et al., 2013) produces Ang17 by subsequent cleavage of AngII by the ACE homolog ACE2 (Figure 1). All Angiotensin peptides bind to GPCRs, namely AT1, and AT2 receptors for AngII and Mas receptor for Ang(17), but activate distinct signaling pathways leading to different and often opposite cellular effects (Figure 1). It is generally accepted that the classical ACE/AngII/AT1 axis promotes most of the RAS actions on cardiovascular, renal, and cerebral functions, and that these effects are counteracted by activation of the AT2 receptor (Porrello etal., 2009; McCarthy et al., 2013) and by the "protective" ACE2/Ang(1-7)/Mas axis (Santos et al., 2013).

Beyond cardiovascular functions, several studies have pointed out a role for RAS components in solid tumors including breast tumors (reviewed in George et al., 2010). Breast cancer is the major cause of death by cancer in women worldwide and the occurrence of distant metastasis is a critical event that limits patients survival. While targeted molecular therapies have considerably improved the management of primary breast tumors, these remain poorly effective for the treatment of metastases. The identification of molecular agents that may contribute to breast cancer progression is therefore essential for future development of new therapeutic strategies. Targeting GPCRs is of particular interest because of the availability of specific agonists and antagonists of the receptors. In addition, their cell surface location makes them suitable for blockade by humanized antibodies, a strategy successfully developed for HER2+ breast tumors with trastuzumab (Herceptin ${ }^{\circledR}$ ). Of interest, most components of the RAS are locally expressed in breast tumors and microenvironment (macrophages and vascular cells; Inwang et al., 1997; De Paepe et al., 2001; Tahmasebi et al., 2006; Herr et al., 2008; George et al., 2010) pointing out angiotensin receptors as potential targets in breast cancer.

In this review, we summarize current knowledge on angiotensin receptors (AT1, AT2, and Mas) in breast cancer, and discuss the potential use of angiotensin receptor agonists and antagonists in malignancy.

\section{ANGIOTENSIN RECEPTORS IN CANCER}

G-protein coupled receptors (GPCRs) of the renin-angiotensin system (RAS) system are activated by angiotensin peptides which are produced by angiotensin converting enzyme (ACE). ACE inhibitors (ACEi) have been assessed in cancer to characterize angiotensin functions in tumor growth, angiogenesis, and metastasis, and were shown to inhibit cell proliferation and tumor progression in several cancer models (reviewed in Rosenthal and Gavras, 2009). However, ACEi prevent production of both angiotensin II (AngII) and Ang1-7, thus preventing activation of all angiotensin receptors. Targeting specific angiotensin receptors using selective agonists or antagonists is warranted in order to validate their use to block tumor progression. 


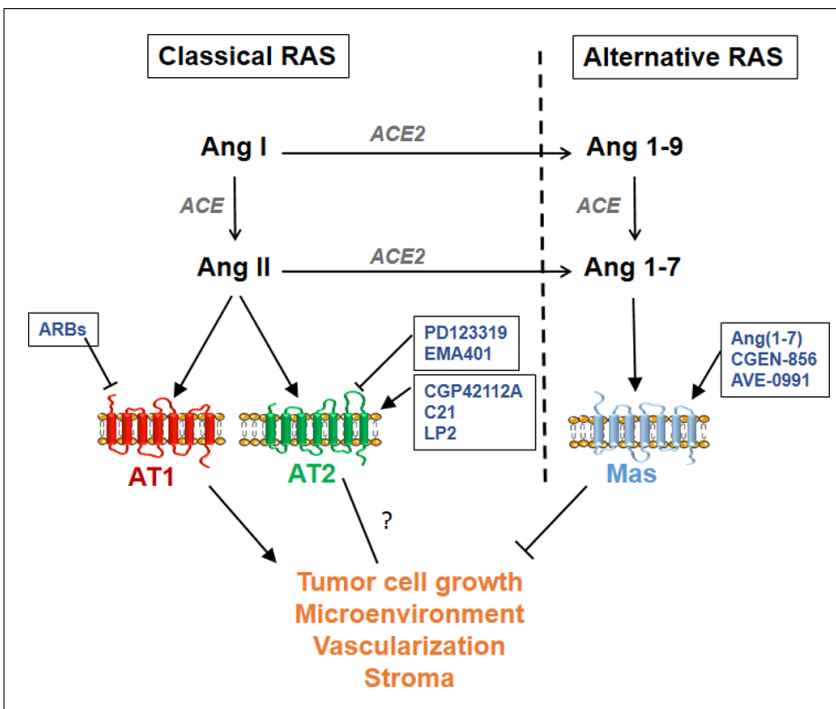

FIGURE 1 | Schematic representation of the classical and alternative renin-angiotensin system (RAS) pathways. Available agonists and antagonists are indicated for each angiotensin G-protein coupled receptor (GPCR): AT1, AT2, and Mas. Available ARBs (AT1 receptor blockers) are Losartan, Candesartan, Valsartan, Irbesartan, Telmisartan, Eprosartan, Olmesartan, and Azilsartan.

\section{AT1 RECEPTOR}

The AT1 receptor is ubiquitously expressed in human tissues and is responsible for most of the AngII actions. AT1 activation by AngII triggers a large number of intracellular effectors leading to modulation of various cell processes, including proliferation, migration, angiogenesis, and inflammation, which are closely associated with tumor progression (Deshayes and Nahmias, 2005). Angiotensin receptor blockers (ARBs), such as losartan, candesartan, or valsartan, have been assayed both in cancer cells and in mouse experimental models to characterize AngII/AT1 functions in tumor growth, angiogenesis, and metastasis (George et al., 2010). Evidence for a role of AT1 receptor on cancer cell metastasis came from in vivo studies of lung models of metastasis. After injection of cancer cells into the tail vein of mice, oral administration of candesartan led to a strong reduction of lung metastasis (Miyajima et al., 2002). However, in this study it was not clear whether ARBs act on tumor cells or on the stromal microenvironment. The role of AT1 in the tumor microenvironment has been investigated by comparing the growth and vascularization of tumors injected subcutaneously into wild type (WT) or AT1 knockout mice (Egami et al., 2003; Fujita et al., 2005; Imai et al., 2007). Tumor growth and vascularization were strongly reduced in AT1 null mice indicating that the AT1 of host cells contributes to both tumor growth and angiogenesis. Of interest, AT1-dependent tumor growth involves an increase in VEGF synthesis, a well-known angiogenic factor (Fujita et al., 2005). Furthermore, AT1 is highly expressed in the stromal tissue surrounding the tumors, in particular in tumorassociated macrophages (TAMs). Macrophage infiltration, as well as levels of TAMs-released VEGF, were strongly reduced in AT1 null mice, supporting the hypothesis that host AT1 might also participate in inflammation-related tumor angiogenesis to maintain tumor growth (Egami etal., 2003; Fujita et al., 2005). In glial tumor patients, AT1 expression was associated with higher proliferation and vascular density and with reduced survival, indicating that AT1-expressing tumors are of poor prognosis (Arrieta et al., 2008).

\section{AT2 RECEPTOR}

Angiotensin II also binds the AT2 receptor subtype but less is known about the functional consequence of AT2 receptor activation in cancer. In vitro studies indicate that over expression of AT2 reduces growth of lung adenocarcinomas cells (Pickel et al., 2010). In agreement, exogenous administration of AT2 receptor by nanoparticles was found to significantly attenuate lung cancer growth in an orthotopic model of syngeneic tumor grafts (Kawabata etal., 2012). AT2 receptor activation using the agonist CGP42112A reduced colorectal liver metastasis (Ager et al., 2010), suggesting that AT2 activation might provide a novel strategy to inhibit tumor growth. Of interest, pancreatic cancer cells subcutaneously injected in AT2 knockout mice grew significantly faster than in WT mice, indicating that AT2 receptors present in the tumor microenvironment may prevent cancer progression (Doi et al., 2010). However, in some other studies, the development of chemically induced sarcoma was delayed in AT2 knockout mice, and AT2 blockade by AT2 antagonist PD123319 significantly reduced lung carcinomas xenografts growth (Clere et al., 2010). Thus, further studies are needed to elucidate AT2 functions in cancer.

Studies on AT2 receptor signaling allowed the identification of several AT2 interacting partners that are related to cancer (Rodrigues-Ferreira et al., 2015). Among them, intracellular proteins of the ATIP family are encoded by candidate tumor suppressor gene MTUS1. MTUS1 was shown to be down regulated in several solid tumors, including from pancreas (Seibold et al., 2003), ovary (Pils et al., 2005), head-and-neck (Ye et al., 2007; Ding et al., 2012), colon (Zuern et al., 2010), bladder (Xiao et al., 2012), and breast (Rodrigues-Ferreira et al., 2009), and ATIPs have been shown to display tumor suppressor effects (Seibold et al., 2003; Rodrigues-Ferreira et al., 2009). Investigating the functional relationship between AT2 and ATIPs might bring more clues toward understanding the effects of AT2 in cancer.

\section{MAS RECEPTOR}

Angiotensins 1-7, the cleavage product of AngII by ACE2, belongs to the alternative RAS pathway and has protective effects on cardiovascular functions (Santos et al., 2013). Ang1-7 is an antiproliferative and anti-angiogenic molecule that mediates its effects by binding to a unique GPCR, Mas (Santos et al., 2003; Passos-Silva et al., 2013).

The anti-proliferative and anti-angiogenic effects of the Ang17/Mas axis in cancer have been evaluated. In vitro studies on lung cancer cells confirmed the anti-proliferative function of Ang1-7 through Mas receptor (Gallagher and Tallant, 2004). In vivo studies further indicated that administration of Ang1-7 reduces lung and prostate tumor xenografts (Gallagher and Tallant, 2004; Menon et al., 2007; Krishnan et al., 2013a), as well as prostate cancer metastasis (Krishnan et al., 2013b). Of interest, Ang1-7 effect on tumor growth was associated with a strong effect on tumor microenvironment. Administration of Ang1-7 has been shown to act on 
endothelial cells to inhibit angiogenesis (Machado et al., 2001; Soto-Pantoja et al., 2009) but also on cancer-associated fibroblasts and osteoclasts to reduce breast cancer fibrosis and metastatic prostate tumor osteoclastogenesis, respectively (Cook et al., 2010; Krishnan et al., 2013b). All in vitro effects of Ang1-7 are inhibited by the Mas receptor antagonist A779 (Machado et al., 2001), suggesting that Mas receptor mediates all protective functions of Ang1-7.

\section{ANGIOTENSIN RECEPTORS IN BREAST CANCER}

In breast tumors, most components of the RAS are expressed (George et al., 2010), suggesting that AngII may be locally produced. Studies from our group aimed at investigating the effect of AngII on breast cancer progression. To this end, metastatic breast cancer cells (D3H2LN) were exposed to AngII in vitro prior to injection into the blood flow of immunodeficient mice (Rodrigues-Ferreira et al., 2012a). Our studies revealed for the first time that AngII can directly act on breast cancer cells to promote cancer cell invasion and metastasis (Rodrigues-Ferreira et al., 2012a). Two major pathways activated by AngII were identified, that were related to cell proliferation and migration/invasion, respectively. These data highlight the importance of defining the role of angiotensin receptors in breast cancer as a first step toward blocking AngII production using ACEi or specifically targeting RAS GPCRs.

\section{AT1}

AT1 has been shown to be expressed both at mRNA and protein levels in normal and malignant breast tissues (De Paepe et al., 2001; Tahmasebi et al., 2006; Herr etal., 2008; Table 1). Functional studies indicated that over expression of AT1 in breast cancer cells promotes cell invasion in vitro and tumor growth in vivo in absence of any stimulation by the AT1 agonist AngII (Rhodes etal., 2009). All these effects were dose-dependently inhibited by the AT1 antagonist losartan confirming the specific role of AT1. Blockade of AT1 by ARBs, such as losartan or candesartan, was shown to inhibit breast cancer cell proliferation in vitro and breast tumor xenograft growth in mice
(Chen et al., 2013), suggesting that AT1 may be an interesting target against breast cancer. Interestingly, in vitro studies demonstrated that AT1 levels are increased in tamoxifen-resistant MCF7 cells as compared to sensitive counterparts, and that tamoxifen sensitivity was restored by blockade of AT1 by losartan (Namazi et al., 2014a,b).

A large-scale meta-analysis performed on 31 breast cancer profiling datasets has revealed over expression of the AT1 receptor gene (AGTR1) in 10-20\% of invasive breast tumors (Rhodes et al., 2009), all of which were estrogen receptor positive (ER+) and human epidermal receptor 2 (HER2)-negative. In another subset of 178 HER2-negative breast tumor patients, high AT1 expression was identified as a marker of resistance to anthracyclin-based neoadjuvant chemotherapy (de Ronde et al., 2013). Recent studies further suggested that high AT1 level may be a predictive marker of bevacizumab response in breast tumors (Sánchez-Rovira et al., 2013; Salvador et al., 2014). Of interest, bevacizumab-induced hypertension in breast cancer patients was also associated with better overall response to this anti-angiogenic therapy (Gampenrieder et al., 2014).

\section{AT2}

AT2 receptor levels have been shown to be markedly increased in breast tumors as compared to normal tissue (De Paepe et al., 2002; Table 1) raising the question of the functional effect of AT2 over expression in breast cancer. To specifically examine this question, we generated a human metastatic breast cancer cell line stably expressing high amounts of human AT2 receptors at the plasma membrane and no detectable AT1 levels (Rodrigues-Ferreira et al., 2012b). This model allows the characterization of AT2 functions independently of those related to AT1 receptor activation, which is of great interest in the context of AT1 blockade by ARBs. It also offers a unique opportunity to evaluate the consequences of AT2 receptor activation and blockade on breast cancer proliferation, invasion, and migration, as well as on tumor growth and metastasis. This model is also suitable to investigate whether AT2 functions may rely on interaction with intracellular partners (RodriguesFerreira etal., 2015). ATIPs are interesting AT2 partners in the

Table 1 | Renin-angiotensin system (RAS) G-protein coupled receptors (GPCRs) in breast cancer.

\begin{tabular}{|c|c|c|c|c|}
\hline Receptor & Detection method & In vivo model & Observation & Reference \\
\hline \multirow[t]{4}{*}{ AT1 } & $\mathrm{IHC} / \mathrm{ISH}$ & & Increased in benign and malignant tumors & De Paepe et al. (2001) \\
\hline & $\mathrm{IHC}$ & & expressed in both ER+ and ER- & Herr etal. (2008) \\
\hline & $\mathrm{FISH} / \mathrm{qPCR}$ & & overexpression in $10-20 \%$ breast carcinomas & Rhodes et al. (2009) \\
\hline & & MCF7 (subcutaneous) & Candesartan reduced tumor growth & Chen et al. (2013) \\
\hline \multirow[t]{2}{*}{ AT2 } & qPCR & & Increased in carcinomas & Tahmasebi et al. (2006) \\
\hline & $\mathrm{IHC} / \mathrm{ISH}$ & & Increased in benign and malignant tumors & De Paepe et al. (2002) \\
\hline \multirow[t]{2}{*}{ MAS } & RT-PCR & & detected in normal and malignant samples & Miller et al. (1997) \\
\hline & & ZR75-1, BT474 (orthotopic) & Ang1-7 reduces tumor growth & Cook et al. (2010) \\
\hline
\end{tabular}

IHC: Immunohistochemistry; ISH: In situ hybridization, qPCR: quantitative PCR; FISH: Fluorescent in situ hybridization. 
context of cancer, as ATIP1 has been shown to reduce proliferation of pancreatic cancer cells (Seibold et al., 2003) whereas ATIP3, which is down-regulated in breast cancer, reduces tumor growth, and metastasis in experimental mice models (Rodrigues-Ferreira et al., 2009). However, whether the consequence of AT2-ATIPs interaction is to promote or prevent breast cancer progression remains to be elucidated.

\section{MAS}

By quantitative RT-PCR, Harmer etal. (2002) found ACE2 expressed in most human cell lines and tissues examined including breast, indicating that Ang 1-7 can be produced in most tissues. Preliminary studies detected Mas receptor at the mRNA level by RT-PCR in both benign and malignant breast tissues (Miller et al., 1997; Table 1). These results need to be validated at the protein level but one can speculate that Mas/Ang1-7 axis is present and targetable in breast tumors. Of interest, in orthotopic breast cancer xenograft models, administration of Ang1-7 efficiently reduced tumor volume and weight (Cook et al., 2010) by acting both on tumor cells and microenvironment. Thus, Ang1-7 may be a useful therapeutic component against breast cancer.

\section{TARGETING ANGIOTENSIN RECEPTORS IN BREAST CANCER}

Preclinical studies thus provide a rationale for the potential use of either ARBs or Mas agonist to treat breast cancer patients. To go further, Ang1-7 and ARBs have been assessed in clinics to evaluate pharmacokinetics in phase I/II trial, and association with breast cancer risk, respectively.

\section{AT1}

Eight different ARBs (Losartan, Candesartan, Valsartan, Irbesartan, Telmisartan, Eprosartan, Olmesartan, and Azilsartan; Figure 1) are currently approved for the treatment of hypertension (Bader et al., 2012) and thus safely used in patients without major side effect, indicating that these ARBs may be reconsidered for the treatment of others pathologies including breast cancer. Several studies evaluated breast cancer risk in ARBs users. Although one study indicated that ARBs are associated with a modest increased risk of new cancer diagnosis (Sipahi et al., 2010), other groups rather reported that $\mathrm{ARBs}$ do not influence the risk of developing a cancer, including breast cancer (Li et al., 2003; Fryzek et al., 2006; ARB Trialists Collaboration, 2011; Azoulay et al., 2012; Bhaskaran et al., 2012; Li et al., 2013). Several studies showed that there is no significant association between the use of ARBs and overall survival of breast cancer patients (Sipahi et al., 2010; Chae et al., 2011; Cardwell et al., 2014). Other analyses indicated that ARBs users with invasive breast cancer have a reduced risk of recurrence (Chae et al., 2011, 2013; Mc Menamin et al., 2012), although in one study ARBs were not associated with breast cancer recurrence (Sørensen et al., 2012), an apparent discrepancy that may reflect variations in AT1 levels among different breast cancer populations examined.

\section{AT2}

Compound C21 is the only non-peptide orally active AT2 receptor agonist tested in several preclinical models with broad potential indication (Unger and Dahlöf, 2010). C21 has been shown to have beneficial effects on blood pressure, cardiac, and kidney functions and inflammation (Steckelings et al., 2011; McCarthy et al., 2013), and its effects in cancer still need to be investigated. Other AT2 ligands are under preclinical development (Bader et al., 2012). In particular the AT2 agonist LP2 compound (Lanthio Pharma) is under evaluation in heart and lung injury (Wagenaar et al., 2013). AT2 antagonists such as PD123319 and its orally active derivative EMA401 were also investigated. Of interest, the highly selective AT2 antagonist EMA401 is under development as a novel neuropathic pain therapeutic agent (Rice et al., 2014). Thus, tools to either block or activate the AT2 receptor (Figure 1) are under development but preclinical studies are still needed to elucidate AT2 functions in cancer and to adequately target this receptor, in particular in breast cancer.

\section{MAS}

Targeting Mas receptor is a promising therapeutic option. Ang1-7 was evaluated in phase I clinical study involving eighteen patients with advanced solid tumors from colon, lung, pancreas, prostate, and soft tissues (Petty et al., 2009). Only mild toxicity was observed for high doses of Ang1-7 administrated subcutaneously (Petty et al., 2009). Of interest, in this study Ang1-7 treatment led to clinical benefit for four patients. In a phase I/II clinical study, Ang1-7 was administered before and after chemotherapy in breast cancer patients with no dose-limiting toxicity (Rodgers et al., 2006). These clinical studies suggest that Ang1-7 may be used in patients without major side effect. To go further, new tools to target Mas receptor are under development. These include orally active Ang1-7 derivatives and new Mas agonists such as the peptidic compound CGEN-856 and the non-peptidic AVE0991 compound (Figure 1; Bader et al., 2012; Ferreira et al., 2012). Of note, patents were developed for the use of Ang1-7 as anticancer and chemopreventive agents able to prevent and reduce cancer growth, including in breast cancer (Tallant et al., 2011; Tallant and Gallagher, 2014).

\section{CONCLUSION}

Angiotensin GPCRs appear as good therapeutic targets expressed at the cell surface and thus easily targetable with pharmacological drugs or humanized blocking antibodies. ARBs are already widely used to treat hypertension and may be safely used in other therapeutic applications, such as breast cancer, in combination with standard treatments. Targeting angiotensin receptors may be promising in several aspects, since beneficial effects of ARBs and Ang1-7 were observed on both tumor cells and tumor microenvironment (Cook et al., 2010; Chen et al., 2013). ARBs and Ang1-7 were also shown to reduce collagen secretion and deposition (Cook et al., 2010; Diop-Frimpong et al., 2011), enhancing drug delivery and potentiating chemotherapy (DiopFrimpong etal., 2011; Chauhan et al., 2013). These interesting results open the way to the use of ARBs/Ang1-7 in complement with chemotherapy to improve their efficiency. Of note, protective effects of ARBs in cancer may be potentiated by Mas activation, as suggested in studies of vascular remodeling (Iwai et al., 2012). In addition, ARBs have been shown to reduce cardiotoxicity of anthracyclin-based chemotherapy of breast cancer (Thakur and Witteles, 2014), whereas Ang(1-7) reduces cytopenia 
of ovarian cancer patients treated with gemcitabine/platinumbased chemotherapy (Pham etal., 2013). Thus using ARBs or Ang1-7 combined with chemotherapy may constitute an interesting strategy to both increase drug efficiency and reduce its side effects.

Future studies should be designed to further evaluate angiotensin receptor levels in breast tumors, in an attempt to select a population of patients that express high levels of AT1 or Mas receptors and may thus benefit from GPCR-targeted therapy.

\section{ACKNOWLEDGMENTS}

This work was supported by the Inserm, the Institut Gustave Roussy, the association Odyssea and Prolific.

\section{REFERENCES}

Ager, E. I., Chong, W. W., Wen, S. W., and Christophi, C. (2010). Targeting the angiotensin II type 2 receptor (AT2R) in colorectal liver metastases. Cancer Cell Int. 10, 19-30. doi: 10.1186/1475-2867-10-19

ARB Trialists Collaboration. (2011). Effects of telmisartan, irbesartan, valsartan, candesartan, and losartan on cancers in 15 trials enrolling 138,769 individuals. J. Hypertens. 29, 623-635. doi: 10.1097/HJH.0b013e328344a7de

Arrieta, O., Pineda-Olvera, B., Guevara-Salazar, P., Hernández-Pedro, N., MoralesEspinosa, D., Cerón-Lizarraga, T. L., et al. (2008). Expression of AT1 and AT2 angiotensin receptors in astrocytomas is associated with poor prognosis. $\mathrm{Br}$. J. Cancer 99, 160-166. doi: 10.1038/sj.bjc.6604431

Azoulay, L., Assimes, T. L., Yin, H., Bartels, D. B., Schiffrin, E. L., and Suissa, S. (2012). Long-term use of angiotensin receptor blockers and the risk of cancer. PLoS ONE 7:e50893. doi: 10.1371/journal.pone.0050893

Bader, M., Santos, R. A., Unger, T., and Steckelings, U. M. (2012). New therapeutic pathways in the RAS. J. Renin Angiotensin Aldosterone Syst. 13, 505-508. doi: $10.1177 / 1470320312466519$

Bhaskaran, K., Douglas, I., Evans, S., van Staa, T., and Smeeth, L. (2012). Angiotensin receptor blockers and risk of cancer: cohort study among people receiving antihypertensive drugs in UK General Practice Research Database. BMJ. 344, e2697. doi: 10.1136/bmj.e2697

Cardwell, C. R., Mc Menamin, Ú. C., Hicks, B. M., Hughes, C., Cantwell, M. M., Murray, L. J. (2014). Drugs affecting the renin-angiotensin system and survival from cancer: a population based study of breast, colorectal, and prostate cancer patient cohorts. BMC Med. 12:28. doi: 10.1186/17417015-12-28

Chae, Y. K., Brown, E. N., Lei, X., Melhem-Bertrandt, A., Giordano, S. H., Litton, J. K., et al. (2013). Use of ACE inhibitors and angiotensin receptor blockers and primary breast cancer outcomes. J. Cancer 4, 549-556. doi: 10.7150/jca.6888

Chae, Y. K., Valsecchi, M. E., Kim, J., Bianchi, A. L., Khemasuwan, D., Desai, A., et al. (2011). Reduced risk of breast cancer recurrence in patients using ACE inhibitors, ARBs, and/or statins. Cancer Invest. 29, 585-593. doi: 10.3109/07357907.2011.616252

Chauhan, V. P., Martin, J. D., Liu, H., Lacorre, D. A., Jain, S. R., and Kozin, S. V., et al. (2013). Angiotensin inhibition enhances drug delivery and potentiates chemotherapy by decompressing tumour blood vessels. Nat. Commun. 4 , 2516. doi: 10.1038/ncomms3516

Chen, X., Meng, Q., Zhao, Y., Liu, M., Li, D., Yang, Y., et al. (2013). Angiotensin II type 1 receptor antagonists inhibit cell proliferation and angiogenesis in breast cancer. Cancer Lett. 328, 318-324. doi: 10.1016/j.canlet.2012.10.006

Clere, N., Corre, I., Faure, S., Guihot, A. L., Vessières, E., Chalopin, M., et al. (2010). Deficiency or blockade of angiotensin II type 2 receptor delays tumorigenesis by inhibiting malignant cell proliferation and angiogenesis. Int. J. Cancer 127, 2279-2291. doi: 10.1002/ijc.25234

Cook, K. L., Metheny-Barlow, L. J., Tallant, E. A., and Gallagher, P. E. (2010). Angiotensin-(1-7) reduces fibrosis in orthotopic breast tumors. Cancer Res. 70, 8319-8328. doi: 10.1158/0008-5472.CAN-10-1136

Crowley, S. D., and Coffman, T. M. (2012). Recent advances involving the renin-angiotensin system. Exp. Cell Res. 318, 1049-1056. doi: 10.1016/j.yexcr.2012.02.023

De Paepe, B., Verstraeten, V. L., De Potter, C. R., Vakaet, L. A., and Bullock, G. R. . (2001). Growth stimulatory angiotensin II type-1 receptor is upregulated in breast hyperplasia and in situ carcinoma but not in invasive carcinoma. Histochem. Cell Biol. 116, 247-254. doi: 10.1007/s004180100313

De Paepe, B., Verstraeten, V. M., De Potter, C. R., and Bullock, G. R. (2002). Increased angiotensin II type-2 receptor density in hyperplasia, DCIS, and invasive carcinoma of the breast is paralleled with increased iNOS expression. Histochem. Cell Biol. 117, 13-19. doi: 10.1007/s00418-001-0356-0

de Ronde, J. J., Lips, E. H., Mulder, L., Vincent, A. D., Wesseling, J., Nieuwland, M., et al. (2013). SERPINA6, BEX1, AGTR1, SLC26A3, and LAPTM4B are markers of resistance to neoadjuvant chemotherapy in HER2-negative breast cancer. Breast Cancer Res. Treat. 137, 213-223. doi: 10.1007/s10549-012-2340-x

Deshayes, F., and Nahmias, C. (2005). Angiotensin II receptors: a new role in cancer? Trends Endocrinol. Metab. 16, 293-299. doi: 10.1016/j.tem.200 5.07 .009

Ding, X., Zhang, N., Cai, Y., Li, S., Zheng, C., Jin, Y., et al. (2012). Down-regulation of tumor suppressor MTUS1/ATIP is associated with enhanced proliferation, poor differentiation, and poor prognosis in oral tongue squamous cell carcinoma. Mol. Oncol. 6, 73-80. doi: 10.1016/j.molonc.2011.11.002

Diop-Frimpong, B., Chauhan, V. P., Krane, S., Boucher, Y., and Jain, R. K. (2011). Losartan inhibits collagen I synthesis and improves the distribution and efficacy of nanotherapeutics in tumors. Proc. Natl. Acad. Sci. U.S.A. 108, 2909-2914. doi: 10.1073/pnas. 1018892108

Doi, C., Egashira, N., Kawabata, A., Maurya, D. K., Ohta, N., Uppalapati, D., et al. (2010). Angiotensin II type 2 receptor signaling significantly attenuates growth of murine pancreatic carcinoma grafts in syngeneic mice. BMC Cancer 10:67. doi: 10.1186/1471-2407-10-67

Egami, K., Murohara, T., Shimada, T., Sasaki, K., Shintani, S., Sugaya, T., et al. (2003). Role of host angiotensin II type 1 receptor in tumor angiogenesis and growth. J. Clin. Invest. 112, 67-75. doi: 10.1172/JCI16645

Ferreira, A. J., Bader, M., and Santos, R. A. (2012). Therapeutic targeting of the angiotensin-converting enzyme 2/Angiotensin-(1-7)/Mas cascade in the reninangiotensin system: a patent review. Expert Opin. Ther. Pat. 22, 567-574. doi: 10.1517/13543776.2012.682572

Fryzek, J. P., Poulsen, A. H., Lipworth, L., Pedersen, L., Nørgaard, M., McLaughlin, J. K., et al. (2006). A cohort study of antihypertensive medication use and breast cancer among Danish women. Breast Cancer Res. Treat. 97, 231-236. doi: 10.1007/s10549-005-9091-x

Fujita, M., Hayashi, I., Yamashina, S., Fukamizu, A., Itoman, M., and Majima, M. (2005). Angiotensin type la receptor signaling-dependent induction of vascular endothelial growth factor in stroma is relevant to tumor-associated angiogenesis and tumor growth. Carcinogenesis 26, 271-279. doi: 10.1093/carcin/bgh324

Gallagher, P. E., and Tallant, E. A. (2004). Inhibition of human lung cancer cell growth by angiotensin-(1-7). Carcinogenesis 25, 2045-2052. doi: 10.1093/carcin/bgh236

Gampenrieder, S. P., Romeder, F., Muß, C., Pircher, M., Ressler, S., Rinnerthaler, G., et al. (2014). Hypertension as a predictive marker for bevacizumab in metastatic breast cancer: results from a retrospective matched-pair analysis. Anticancer. Res. $34,227-233$.

George, A. J., Thomas, W. G., and Hannan, R. D. (2010). The renin-angiotensin system and cancer: old dog, new tricks. Nat. Rev. Cancer 10, 745-759. doi: $10.1038 / \mathrm{nrc} 2945$

Harmer, D., Gilbert, M., Borman, R., and Clark, K. L. (2002). Quantitative mRNA expression profiling of ACE 2, a novel homologe of angiotensin converting enzyme. FEBS Lett. 532, 107-110. doi: 10.1016/S0014-5793(02)03640-2

Herr, D., Rodewald, M., Fraser, H. M., Hack, G., Konrad, R., Kreienberg, R., et al. (2008). Potential role of Renin-Angiotensin-system for tumor angiogenesis in receptor negative breast cancer. Gynecol. Oncol. 109, 418-425. doi: 10.1016/j.ygyno.2008.02.019

Imai, N., Hashimoto, T., Kihara, M., Yoshida, S., Kawana, I., Yazawa, T., et al. (2007). Roles for host and tumor angiotensin II type 1 receptor in tumor growth and tumor-associated angiogenesis. Lab. Invest. 87, 189-198. doi: 10.1038/labinvest. 3700504

Inwang, E. R., Puddefoot, J. R., Brown, C. L., Goode, A. W., Marsigliante, S., Ho, M. M., et al. (1997). Angiotensin II type 1 receptor expression in human breast tissues. Br. J. Cancer 75, 1279-1283. doi: 10.1038/bjc.1997.217

Iwai, M., Nakaoka, H., Senba, I., Kanno, H., Moritani, T., and Horiuchi, M. (2012). Possible involvement of angiotensin-converting enzyme 2 and Mas activation in inhibitory effects of angiotensin II Type 1 receptor blockade on vascular remodeling. Hypertension 60, 137-144. doi: 10.1161/HYPERTENSIONAHA.112. 191452 
Kawabata, A., Baoum, A., Ohta, N., Jacquez, S., Seo, G. M., Berkland, C., et al. (2012). Intratracheal administration of a nanoparticle-based therapy with the angiotensin II type 2 receptor gene attenuates lung cancer growth. Cancer Res. 72 , 2057-2067. doi: 10.1158/0008-5472.CAN-11-3634

Krishnan, B., Torti, F. M., Gallagher, P. E., and Tallant, E. A. (2013a). Angiotensin(1-7) reduces proliferation and angiogenesis of human prostate cancer xenografts with a decrease in angiogenic factors and an increase in sFlt-1. Prostate 73, 60-70. doi: 10.1002 /pros. 22540

Krishnan, B., Smith, T. L., Dubey, P., Zapadka, M. E., Torti, F. M., Willingham, M. C., et al. (2013b). Angiotensin-(1-7) attenuates metastatic prostate cancer and reduces osteoclastogenesis. Prostate 73, 71-82. doi: 10.1002/pros.22542

Li, C. I., Daling, J. R., Tang, M. T., Haugen, K. L., Porter, P. L., Malone, K. E. (2013). Use of antihypertensive medications and breast cancer risk among women aged 55 to 74 years. JAMA Intern. Med. 173, 1629-1637. doi: 10.1001/jamainternmed.2013.9071

Li, C. I., Malone, K. E., Weiss, N. S., Boudreau, D. M., Cushing-Haugen, K. L., and Daling, J. R. (2003). Relation between use of antihypertensive medications and risk of breast carcinoma among women ages 65-79 years. Cancer 98, 1504-1513. doi: $10.1002 / \mathrm{cncr} .11663$

Machado, R. D., Santos, R. A., and Andrade, S. P. (2001). Mechanisms of angiotensin-(1-7)-induced inhibition of angiogenesis. Am. J. Physiol. Regul. Integr. Comp. Physiol. 280, R994-R1000.

McCarthy, C. A., Widdop, R. E., Denton, K. M., and Jones, E. S. (2013). Update on the angiotensin AT(2) receptor. Curr. Hypertens. Rep. 15, 25-30. doi: 10.1007/s11906012-0321-4

Mc Menamin, Ú. C., Murray, L. J., Cantwell, M. M., and Hughes, C. M. (2012) Angiotensin-converting enzyme inhibitors and angiotensin receptor blockers in cancer progression and survival: a systematic review. Cancer Causes Control 23, 221-230. doi: 10.1007/s10552-011-9881-x

Menon, J., Soto-Pantoja, D. R., Callahan, M. F., Cline, J. M., Ferrario, C. M., Tallant, E. A., et al. (2007). Angiotensin-(1-7) inhibits growth of human lung adenocarcinoma xenografts in nude mice through a reduction in cyclooxygenase-2. Cancer Res. 67, 2809-2815. doi: 10.1158/0008-5472.CAN-06-3614

Miller, N., McCann, A. H., O’Connell, D., Pedersen, I. S., Spiers, V., Gorey, T., et al. (1997). The MAS proto-oncogene is imprinted in human breast tissue. Genomics 46, 509-512. doi: 10.1006/geno.1997.5063

Miyajima, A., Kosaka, T., Asano, T., Asano, T., Seta, K., Kawai, T., et al (2002). Angiotensin II type I antagonist prevents pulmonary metastasis of murine renal cancer by inhibiting tumor angiogenesis. Cancer Res. 62, 4176-4179.

Namazi, S., Rostami-Yalmeh, J., Sahebi, E., Jaberipour, M., Razmkhah, M., and Hosseini, A. (2014a). The role of captopril and losartan in prevention and regression of tamoxifen-induced resistance of breast cancer cell line MCF-7: an in vitro study. Biomed. Pharmacother. 68, 565-571. doi: 10.1016/j.biopha.201 4.05.004

Namazi, S., Sahebi, E., Rostami-Yalmeh, J., Jaberipour, M., Razmkhah, M., Hosseini, A., et al. (2014b). Effect of angiotensin receptor blockade on prevention and reversion of tamoxifen-resistant phenotype in MCF-7 cells. Tumour Biol. doi: 10.1007/s13277-014-2713-3 [Epub ahead of print].

Passos-Silva, D. G., Verano-Braga, T., and Santos, R. A. (2013). Angiotensin(1-7): beyond the cardio-renal actions. Clin. Sci. (Lond.). 124, 443-456. doi: 10.1042/CS20120461

Petty, W. J., Miller, A. A., McCoy, T. P., Gallagher, P. E., Tallant, E. A., and Torti, F. M. (2009). Phase I and pharmacokinetic study of angiotensin-(1-7), an endogenous antiangiogenic hormone. Clin. Cancer Res. 15, 7398-7404. doi: 10.1158/10780432.CCR-09-1957

Pickel, L., Matsuzuka, T., Doi, C., Ayuzawa, R., Maurya, D. K., Xie, S. X., et al. (2010). Overexpression of angiotensin II type 2 receptor gene induces cell death in lung adenocarcinoma cells. Cancer Biol. Ther. 9, 277-285. doi: 10.4161/cbt.9.4.10643

Pils, D., Horak, P., Gleiss, A., Sax, C., Fabjani, G., and Moebus, V. J., et al. (2005). Five genes from chromosomal band $8 \mathrm{p} 22$ are significantly down-regulated in ovarian carcinoma: N33 and EFA6R have a potential impact on overall survival. Cancer 104, 2417-2429. doi: 10.1002/cncr.21538

Pham, H., Schwartz, B. M., Delmore, J. E., Reed, E., Cruickshank, S., Drummond, L., et al. (2013). Pharmacodynamic stimulation of thrombogenesis by angiotensin (1-7) in recurrent ovarian cancer patients receiving gemcitabine and platinum-based chemotherapy. Cancer Chemother. Pharmacol. 71, 965-972. doi: $10.1007 /$ s00280-013-2089-x
Porrello, E. R., Delbridge, L. M., and Thomas, W. G. (2009). The angiotensin II type 2 (AT2) receptor: an enigmatic seven transmembrane receptor. Front. Biosci. (Landmark Ed). 14:972. doi: 10.2741/3289

Rhodes, D. R., Ateeq, B., Cao, Q., Tomlins, S. A., Mehra, R., Laxman, B., et al. (2009). AGTR1 overexpression defines a subset of breast cancerand confers sensitivity to losartan, an AGTR1 antagonist. Proc. Natl. Acad. Sci. U.S.A. 106, 10284-10289. doi: 10.1073/pnas.0900351106

Rice, A. S., Dworkin, R. H., McCarthy, T. D., Anand, P., Bountra, C., McCloud, P. I., etal. (2014). EMA401, an orally administered highly selective angiotensin II type 2 receptor antagonist, as a novel treatment for postherpetic neuralgia: a randomised, double-blind, placebo-controlled phase 2 clinical trial. Lancet 383, 1637-1647. doi: 10.1016/S0140-6736(13) 62337-5

Rodgers, K. E., Oliver, J., and diZerega, G. S. (2006). Phase I/II dose escalation study of angiotensin 1-7 [A (1-7)] administered before and after chemotherapy in patients with newly diagnosed breast cancer. Cancer Chemother. Pharmacol. 57, 559-568. doi: 10.1007/s00280-00 5-0078-4

Rodrigues-Ferreira, S., Abdelkarim, M., Dillenburg-Pilla, P., Luissint, A. C., diTommaso, A., Deshayes, F., et al. (2012a). Angiotensin II facilitates breast cancer cell migration and metastasis. PLoS ONE 7:e35667-e35674. doi: 10.1371/journal.pone.0035667

Rodrigues-Ferreira, S., Morel, M., Reis, R. I., Cormier, F., Baud, V., Costa-Neto, C. M., et al. (2012b). A novel cellular model to study angiotensin ii at 2 receptor function in breast cancer cells. Int. J. Peptides 2012, 1-6. doi: 10.1155/2012/ 745027

Rodrigues-Ferreira, S., Di Tommaso, A., Dimitrov, A., Cazaubon, S., Gruel, N., Colasson, H., etal. (2009). 8p22 MTUS1 gene product ATIP3 is a novel anti-mitotic protein underexpressed in invasive breast carcinoma of poor prognosis. PLoS ONE 4:e7239. doi: 10.1371/journal.pone.00 07239

Rodrigues-Ferreira, S., Molina, A., Nehlig, A., Nahmias, C. (2015). “The AT2 receptor and interacting proteins ATIPs in cancer," in The Protective Arm of the Renin Angiotensin System (RAS): Functional Aspects and Therapeutic Implications, eds T. Unger, U. M. Steckelings, and R. A. Santos (Amsterdam: Elsevier Press).

Rosenthal, T., and Gavras, I. (2009). Angiotensin inhibition and malignancies: a review. J. Hum. Hypertens. 23, 623-635. doi: 10.1038/ jhh.2009.21

Salvador, J., Manso, L., de la Haba, J., Jaen, A., Ciruelos, E., de Villena, M. C., et al. (2014). Final results of a phase II study of paclitaxel, bevacizumab, and gemcitabine as first-line therapy for patients with HER2-negative metastatic breast cancer. Clin. Transl. Oncol. doi: 10.1007/s10549-010-1002-0 [Epub ahead of print].

Sánchez-Rovira, P., Seguí, M. A., Llombart, A., Aranda, E., Antón, A., Sánchez, A., et al. (2013). Bevacizumab plus preoperative chemotherapy in operable HER2 negative breast cancer: biomarkers and pathologic response. Clin. Transl. Oncol. 15, 810-817. doi: 10.1007/s12094-013-1006-4

Santos, R. A., Ferreira, A. J., Verano-Braga, T., and Bader, M. (2013). Angiotensin-converting enzyme 2, Angiotensin-(1-7) and Mas: new players of the Renin Angiotensin System. J. Endocrinol. 216, R1-R17. doi: 10.1530/JOE12-0341

Santos, R. A., Simoes e Silva, A. C., Maric, C., Silva, D. M., Machado, R. P., de Buhr, I., etal. (2003). Angiotensin-(1-7) is an endogenous ligand for the $\mathrm{G}$ protein-coupled receptor Mas. Proc. Natl. Acad. Sci. U.S.A. 100, 8258-8263. doi: 10.1073/pnas.1432869100

Seibold, S., Rudroff, C., Weber, M., Galle, J., Wanner, C., and Marx, M. (2003). Identification of a new tumor suppressor gene located at chromosome 8p21.3-22. FASEB J. 17, 1180-1182.

Sipahi, I., Debanne, S. M., Rowland, D. Y., Simon, D. I., and Fang, J. C. (2010). Angiotensin-receptor blockade and risk of cancer: meta-analysis of randomised controlled trials. Lancet Oncol. 11, 627-636. doi: 10.1016/S1470-2045(10) 70106-6

Sørensen, G. V., Ganz, P. A., Cole, S. W., Pedersen, L. A., Sørensen, H. T., CroninFenton, D. P., et al. (2012). Use of $\beta$-blockers, angiotensin-converting enzyme inhibitors, angiotensin II receptor blockers, and risk of breast cancer recurrence: a Danish nationwide prospective cohort study. J. Clin. Oncol. 31, 2265-2272. doi: 10.1200/JCO.2012.43.9190 
Soto-Pantoja, D. R., Menon, J., Gallagher, P. E., and Tallant, E. A. (2009). Angiotensin-(1-7) inhibits tumor angiogenesis in human lung cancer xenografts with a reduction in vascular endothelial growth factor. Mol. Cancer Ther. 8, 1676-1683. doi: 10.1158/1535-7163.MCT09-0161

Steckelings, U. M., Larhed., M., Hallberg, A., Widdop, R. E., Jones, E. S., Wallinder, C., et al. (2011). Non-peptide AT2-receptor agonists. Curr. Opin. Pharmacol. 11, 187-192. doi: 10.1016/j.coph.2010.11.002

Tahmasebi, M., Barker, S., Puddefoot, J. R., and Vinson, G. P. (2006). Localisation of renin-angiotensin system (RAS) components in breast. Br. J. Cancer 95, 67-74. doi: 10.1038/sj.bjc.6603213

Tallant, E. A., and Gallagher, P. E. (2014). Angiotensin-(1-7) As a Chemoprevention Agent. Patent number: 20140296143.

Tallant, E. A., Gallagher, P. E., and Ferrario, C. M. (2011). Angiotensin-(1-7) and angiotensin-(1-7) agonists for inhibition of cancer cell growth. Patent number: 8034781. doi: 10.1111/j.1476-5381.2012.01905.x

Thakur, A., and Witteles, R. M. (2014). Cancer therapy-induced left ventricular dysfunction: interventions and prognosis. J. Card. Fail. 20, 155-158. doi: 10.1016/j.cardfail.2013.12.018

Unger, T., and Dahlöf, B. (2010). Compound 21, the first orally active, selective agonist of the angiotensin type 2 receptor (AT2): implications for AT2 receptor research and therapeutic potential. J. Renin Angiotensin Aldosterone Syst. 11, 7577. doi: $10.1177 / 1470320309347792$

Wagenaar, G. T., Laghmani, el H., Fidder, M., Sengers, R. M., de Visser, Y. P., de Vries, L., et al. (2013). Agonists of MAS oncogene and angiotensin II type 2 receptors attenuate cardiopulmonary disease in rats withneonatal hyperoxiainduced lung injury. Am. J. Physiol. Lung. Cell Mol. Physiol. 305, L341-L351. doi: 10.1152/ajplung.00360.2012
Xiao, J., Chen, J. X., Zhu, Y. P., Zhou, L. Y., Shu, Q. A., and Chen, L. W. (2012) Reduced expression of MTUS1 mRNA is correlated with poor prognosis in bladder cancer. Oncol. Lett. 4, 113-118.

Ye, H., Pungpravat, N., Huang, B. L., Muzio, L. L., Mariggiò, M. A., Chen, Z., et al. (2007). Genomic assessments of the frequent loss of heterozygosity region on 8p21.3-8p22 in head and neck squamous cell carcinoma. Cancer Genet. Cytogenet 176, 100-106. doi: 10.1016/j.cancergencyto.2007.04.003

Zuern, C., Heimrich, J., Kaufmann, R., Richter, K. K., Settmacher, U., Wanner, C., et al. (2010) Down-regulation of MTUS1 in human colon tumors. Oncol. Rep. 23, 183-189.

Conflict of Interest Statement: The authors declare that the research was conducted in the absence of any commercial or financial relationships that could be construed as a potential conflict of interest.

Received: 19 December 2014; paper pending published: 20 January 2015; accepted: 30 January 2015; published online: 17 February 2015.

Citation: Rodrigues-Ferreira $S$ and Nahmias C (2015) G-protein coupled receptors of the renin-angiotensin system: new targets against breast cancer? Front. Pharmacol. 6:24. doi: 10.3389/fphar.2015.00024

This article was submitted to Experimental Pharmacology and Drug Discovery, a section of the journal Frontiers in Pharmacology.

Copyright (c) 2015 Rodrigues-Ferreira and Nahmias. This is an open-access article distributed under the terms of the Creative Commons Attribution License (CC BY). The use, distribution or reproduction in other forums is permitted, provided the original author(s) or licensor are credited and that the original publication in this journal is cited, in accordance with accepted academic practice. No use, distribution or reproduction is permitted which does not comply with these terms. 